\title{
Stability Analysis and Reliability Evaluation in Cataclastic Loose Rock Mass Blocks
}

\author{
Liguo Zhang, ${ }^{1,2}$ Dong Wang, ${ }^{1}$ Guanghe Li, ${ }^{1}$ Jiaxing Dong $\mathbb{D}^{3},{ }^{3}$ and Jianpeng Zhang ${ }^{4}$ \\ ${ }^{1}$ College of Mines, Liaoning Technical University, Fuxin, Liaoning 123000, China \\ ${ }^{2}$ Yunnan Minbao-Kungong Blasting Engineering Co., Ltd., Kunming, Yunnan 650093, China \\ ${ }^{3}$ Faculty of Electric Power Engineering, Kunming University of Science and Technology, Kunming, Yunnan 650500, China \\ ${ }^{4}$ Planning and Development Department, Ben Gang Group Corporation, Benxi, Liaoning 117000, China \\ Correspondence should be addressed to Jiaxing Dong; dong1986@kust.edu.cn
}

Received 6 January 2020; Revised 16 November 2020; Accepted 2 December 2020; Published 4 January 2021

Academic Editor: Wenbing Wu

Copyright ( $\odot 2021$ Liguo Zhang et al. This is an open access article distributed under the Creative Commons Attribution License, which permits unrestricted use, distribution, and reproduction in any medium, provided the original work is properly cited.

\begin{abstract}
Cataclastic rock masses with multiple failure modes and mechanisms are critical geological problems in the construction of rock slopes. Cataclastic rock masses are widely distributed in slopes of a hydropower project located on Lancang River, which is located in Tibet, China. In this study, the potentially unstable block of the slope is divided into key block and secondary key block based on the key block theory, and the system reliability evaluation theory is introduced. The method for quantitatively analyzing the rock mass stability of cataclastic slopes with sliding failure is established. Then, the spatial distribution of cataclastic rock masses and discontinuities in several rock slopes of a hydropower project are determined using traditional geological surveying and 3D laser scanning. At last, combining the BATE 2.0 software and the stereographic projection of the vector, the proposed method is applied to the study area. The results show that the main failure mode of the studied slope is wedge failure, and the system reliability is 1.69 . With the increase in the instability probability of the key block, the increase in the instability probability of the system block is obvious, which reflects the controlling effect of the key block on the stability of the system block. The calculated system instability probability is slightly larger than the key block instability probability.
\end{abstract}

\section{Introduction}

In recent years, rapid economic development has demanded the construction of hydropower projects, highways, railways, and mines. Large hydropower projects of China are mainly distributed in southwestern China, scale and complexity of the rock slopes in these projects are unprecedented, with complex and changeable geological problems. Specifically, the geological conditions are complex, the slope rock mass always has poor stability, the engineering slope is high and steep, the effects of slope engineering are complicated and difficult to control, and the rigid standard of controlling slope engineering safety results in a large economic investment with a long construction period.

The main areas of research on high rock slopes mainly include geological conditions, stability analysis methods, control standards, reinforcement design, implementation control, and their effects in different conditions [1-5].
Geological conditions are the basis of slope stability, which include the stages of exploration, design, construction, and operation. The specific research contents include the characteristics of the slope rock mass, physical and mechanical properties, geological analysis, slope deformation and failure modes, and geomechanical mechanisms [6]. Slope stability is affected by numerous factors, such as geological conditions and excavation methods. Rock slope stability assessments are commonly performed by means of kinematical, analytical, and numerical analyses [7]. Since 1970, many rock mass classification systems that consider many affecting factors, such as the slope geometry, presence of water or water pressures, weathering effects, and excavation methods, have been proposed or modified and applied in the quantitative stability prediction of rock engineering [8-14].

A large number of examples show that the joint is the main factor controlling the mechanical response of a rock mass under engineering loads. In mountainous regions 
affected by special climatic environments and topography, cataclastic rock masses formed under the combined effects of freezing, thawing, unloading, and weathering. The evaluation of the stability of cataclastic rock masses is important in rock slope stability assessment, as discontinuities always have strongly random distributions in geometric and mechanical parameters. A stability probability calculation method is proposed based on the research of geological properties and the corresponding analysis. Then, the proposed method is applied to practical engineering, and the results show that the research has important engineering value and theoretical significance.

\section{Concept of a Cataclastic Rock Mass}

A cataclastic rock mass in a hydropower slope was first described by $\mathrm{Wu}$ et al. [15], who noted that a cataclastic rock mass has two meanings. First, the rock mass is fragmented, and the spacings of the joints are generally smaller than $30 \mathrm{~cm}$. Second, the rock mass is loose, i.e., the rock mass was obviously loosened and expanded. In practical engineering, loosely separated rock blocks are generally less than $1 \mathrm{~m}$ and some are 1-2 $\mathrm{m}$. In addition, it is noted that rock masses with a joint spacing greater than $30 \mathrm{~cm}$ are classified as cataclastic rock masses. In some particular zones, such as rock masses with inlaid structures, fault fracture development, or strong weathered zones, although the spacings of the joints are less than $30 \mathrm{~cm}$, the rock mass is closely packed; according to these zones, the rock mass cannot be classified as a cataclastic rock mass. Similarly, the unloading rock mass has a slack phenomenon that cannot be classified as a cataclastic rock mass (see Figure 1, modified after [16]).

\section{Probability Analysis of the System Stability of a Slope Rock Mass}

The key block theory was first proposed by Shi and Goodman [10]. This theory assumes that the block with the joints of the rock mass is a plane, and the block of the joints is a rigid body. The geometry topology method is used to analyze the different rock masses. The type of block that may be unstable on the excavation surface, combined with the mechanical balance analysis of the rigid body. Key block theory has become an important method to solve the problem of discontinuous rock mass stability. The stability problem of cataclastic rock masses is a typical discontinuous rock mass stability problem. It is feasible to use this theoretical analysis from a theoretical point of view.

According to the literature [17-20], in the block stability reliability analysis, the resistance $R$ and the load effect $S$ of the block are mainly considered, and the difference $Q$ between $R$ and $S$ is defined as the safety margin of the block. Then, the block probability of instability of the body can be expressed as follows:

$$
p_{f}=p[Q<0]=p[R-S<0] .
$$

It is assumed that the resistance $R$ and the load effect $S$ of the block satisfy the standard normal distribution and the reliability index $\beta$ of the defined block satisfies

$$
\beta=\Phi^{-1}\left(1-p_{f}\right)
$$

where $\Phi^{-1}(\cdot)$ is the inverse function of the standard normal distribution. Formulas (3)-(5) are the limit state equations for block collapse, single-sided sliding, and double-sided sliding, respectively. In the formula, the block geometry parameters (dips of the jionts in the block $\alpha_{i}$ ) and the joint mechanical parameters (friction factor $f_{i}$ and cohesion $c_{i}$ ) are selected as random variables for reliability calculation. In the wedge failure mode, dips of the joints in the block are $\left(\alpha_{i}, \alpha_{j}\right)$, the friction factor is $\left(f_{i}\right.$, $\left.f_{j}\right)$, the cohesion is $\left(c_{i}, c_{j}\right)$, and dip of the intersection edge is $\delta$, and the intersection angle is $\left(\gamma_{\mathrm{i}}, \gamma_{\mathrm{j}}\right)$. It is assumed that the inclination, friction factor, and cohesion of the joints are subject to a standard normal distribution or a lognormal distribution.

$$
\begin{aligned}
g\left(\alpha_{i}, f_{i}, c_{i}\right) & =W_{i}-c_{i} A_{i} \\
g\left(\alpha_{i}, f_{i}, c_{i}\right) & =W_{i} \cos \alpha_{i} \cdot f_{i}-c_{i} A_{i}-W_{i} \sin \alpha_{i}, \\
g\left(\delta, \gamma_{i}, \gamma_{j}, f_{i}, c_{i}, f_{j}, c_{j}\right) & =W \sin \delta-W \cos \delta \cdot \frac{\sin \gamma_{i}}{\sin \left(\gamma_{i}+\gamma_{j}\right)} \cdot f_{i}-W \cos \delta \cdot \frac{\sin \gamma_{i}}{\sin \left(\gamma_{i}+\gamma_{j}\right)} \cdot f_{i}-c_{i} A_{i}-c_{j} A_{j} .
\end{aligned}
$$

Based on the research results of reference [17] on the stability of the surrounding rock of underground caverns, a cataclastic rock mass should be considered according to the "system-local" mode and the key block theory is normally used. Based on the consideration of analytical ideas, the research focuses on the reliability of key andblockandsecondary key block systems. In the two-dimensional space plane, the reliability calculation method of key blocks is detailed in reference $[14,19]$.

As shown in Figure 2, $e$ is a key block, and $d$ is a possible unstable block and a secondary key block, and its instability directly affects the stability of the entire rock block. According to the conditional probability theory and the 


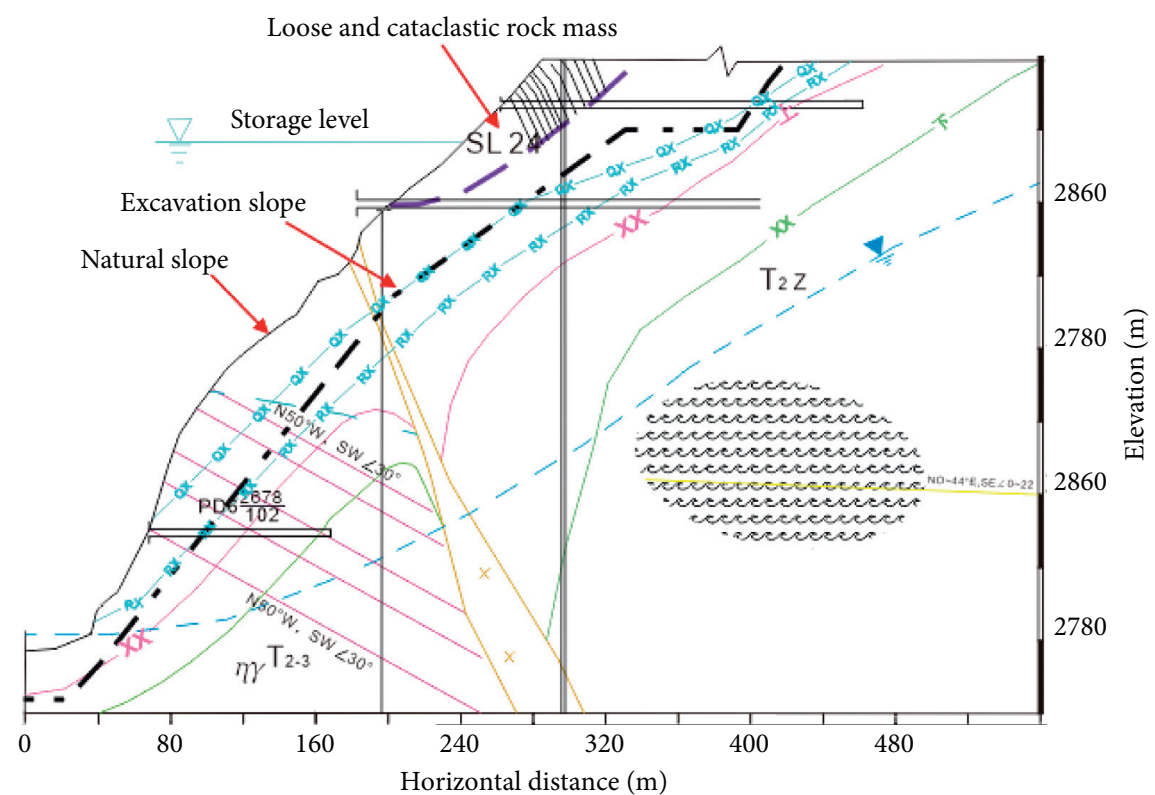

FIgURE 1: Typical loose and cataclastic rock mass and its relationship with slope.

calculated key block reliability, the reliability calculation formula of the secondary key block can be expressed as follows:

$$
\beta_{2}=\Phi^{-1}[1-P(B \mid A)]=\Phi^{-1}\left[1-\frac{P(A B)}{P(A)}\right]=\Phi^{-1}\left[1-\frac{P(A B)}{1-\Phi\left(\beta_{1}\right)}\right]=\Phi^{-1}\left[1-\frac{1-\Phi\left(\beta_{1}^{\prime}\right)}{1-\Phi\left(\beta_{1}\right)}\right] .
$$

In Figure 3, combined with the conditional probability analysis theory, the series system failure probability evaluation formula (7) is introduced, and the reliability index $\beta$ i of each block is obtained step by step and substituted into formula (7). The instability probability of the system can be determined. Finally, the system reliability index is obtained as shown in formula (8).

$$
\begin{aligned}
p_{s} & =p\left\{\bigcup_{i=1}^{n} g_{i}\left(X_{i}\right) \leq 0\right\}=p\left\{\bigcup_{i=1}^{n} g_{i}\left(X_{i}\right) \leq 0\right\}=1-\Phi\left(\beta_{i} ; \rho\right)=\int_{-\infty}^{+\infty} \phi(x)\left[1-\prod_{i=1}^{n} \Phi\left(\frac{\beta_{i}+\sqrt{\rho}}{\sqrt{1-\rho}}\right)\right] \mathrm{d} x, \\
\beta_{s} & =\Phi^{-1}\left(1-p_{s}\right) .
\end{aligned}
$$

\section{Application}

4.1. Engineering Situation. The proposed project is a power station planned in the Lancang River in Tibet, China. Slope stability is one of the key engineering problems in the construction of the project. The maximum height of the excavation slope is $665 \mathrm{~m}$, and the permanent slope above the dam is $350 \mathrm{~m}$. The geological environment is complex and mainly manifests as joint development, strong weathering, and unloading. The problem of the stability of a cataclastic rock mass is a key problem in the engineering of geological and rock mechanics. The traditional geological survey has the defects of large workload and high risk, its spatial distribution is mainly obtained through the interpretation of the results of a three-dimensional laser scanner, and a total number of 21 scans are distributed on the left and right banks (see Figure 4). In this paper, SL24, with the largest distribution area, is selected for research. The fragmented rock mass of SL24 is located on the right bank of the dam axis with an elevation of $2830-3270 \mathrm{~m}$, an area of approximately $122,300 \mathrm{~m}^{2}$, a thickness of $30-50 \mathrm{~m}$, and a volume of approximately $30,580,000 \mathrm{~m}^{3}$. The angle of the natural slope is $35^{\circ}-60^{\circ}$. There is a set of joints with obvious toppling deformation. According to the degree of dumping deformation, this area can be divided into three zones. The first zone is the fall-over accumulation zone, and only the 


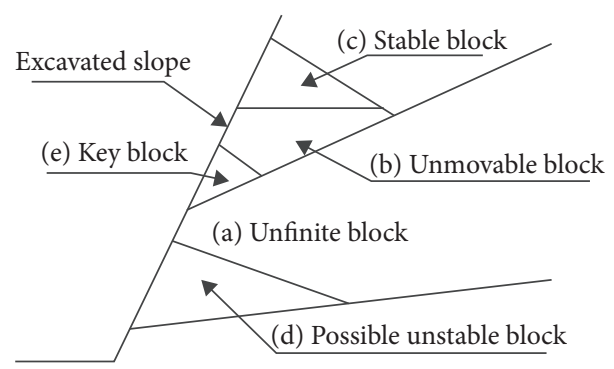

Figure 2: Schematic diagram of rock mass classification of the slope.

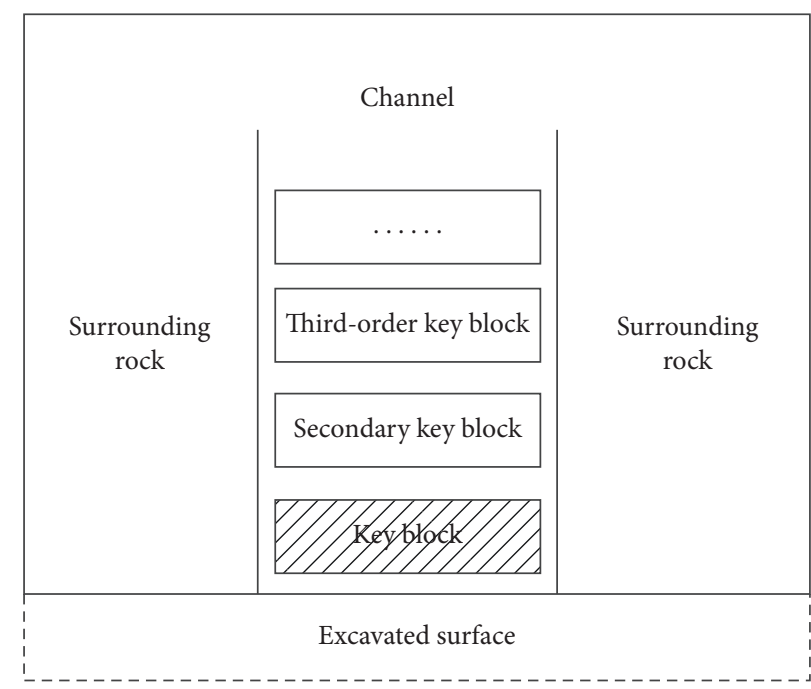

FIgURE 3: Block system model [17].

slope table is scattered; the bulk structure and the block diameter are more than $20 \mathrm{~cm}$. The second zone is the strong dumping zone; the thickness is approximately $3-40 \mathrm{~m}$, and the loose-fragmented structure and the block diameter can be seen in the slice joint and are often caused by excavation disturbance or heavy rainfall. The third zone is a weak dumping zone with partial sliding; the thickness is approximately $3-38 \mathrm{~m}$, and the cut joints developed intermittently. Under the current conditions, the rock mass is stable. Due to engineering construction and excavation disturbance, stability research is particularly important.

\subsection{Geometric Distribution Characteristics of the Joint.} The selection of the physical and mechanical parameters of the joints is the key factor for evaluating the accuracy of the block stability. The geometric parameters involved in this paper include dip, dip direction, trace length, and spacing. These parameters are mainly obtained by the statistical window method according to the traditional geological survey. Because the number of samples is limited, in this paper, we simulated the typical slope rock mass structure using the Monte-Carlo model combined with the results obtained from the statistical window. In the study area, V-level joints mainly developed, which can be divided into three groups, and the number of samples is 36,30 , and 26. The dip direction/dip of each group is as follows: $\mathrm{N} 60^{\circ}-82^{\circ} \mathrm{W} / \mathrm{SW} \angle 43^{\circ}-70^{\circ}$; $\mathrm{N} 45^{\circ}-74^{\circ} \mathrm{E} / \mathrm{NW} \angle 63^{\circ}-85^{\circ}$; and $\mathrm{N} 55^{\circ}-72^{\circ} \mathrm{W} / \mathrm{NE} \angle 50^{\circ}-71^{\circ}$ (see Figure 5). On the basis of the joint classification, statistical analysis was carried out on the probability distribution forms of the geometrical elements of each group of joints (Figures 6 and 7, modified after [21])

It can be seen from Figures 6 and 7 that the dips of the joints of each group basically obey the normal distribution, the dip directions are close to the normal distribution, and the trace length and spacing basically obey the negative exponential distribution. The distribution characteristics of the main joints used for the calculations were surveyed and analyzed as shown in Table 1.

Based on the Monte-Carlo method, with the statistical parameters of the joints listed in Table 1, the plane section, cross-section, and longitudinal section of the measured joints with the same geometric parameters and distribution forms are generated according to a threedimensional network diagram of the direction (Figure 8). Joint network simulation results can lay the foundation for subsequent key block search and block reliability.

4.3. Joint Mechanical Parameters. The shear strength parameters $(c$ and $\varphi$ ) of rock mass joints are generally determined by indoor direct shearing, large-scale shear tests on the surface of the joints, engineering analogies, estimation methods, and 


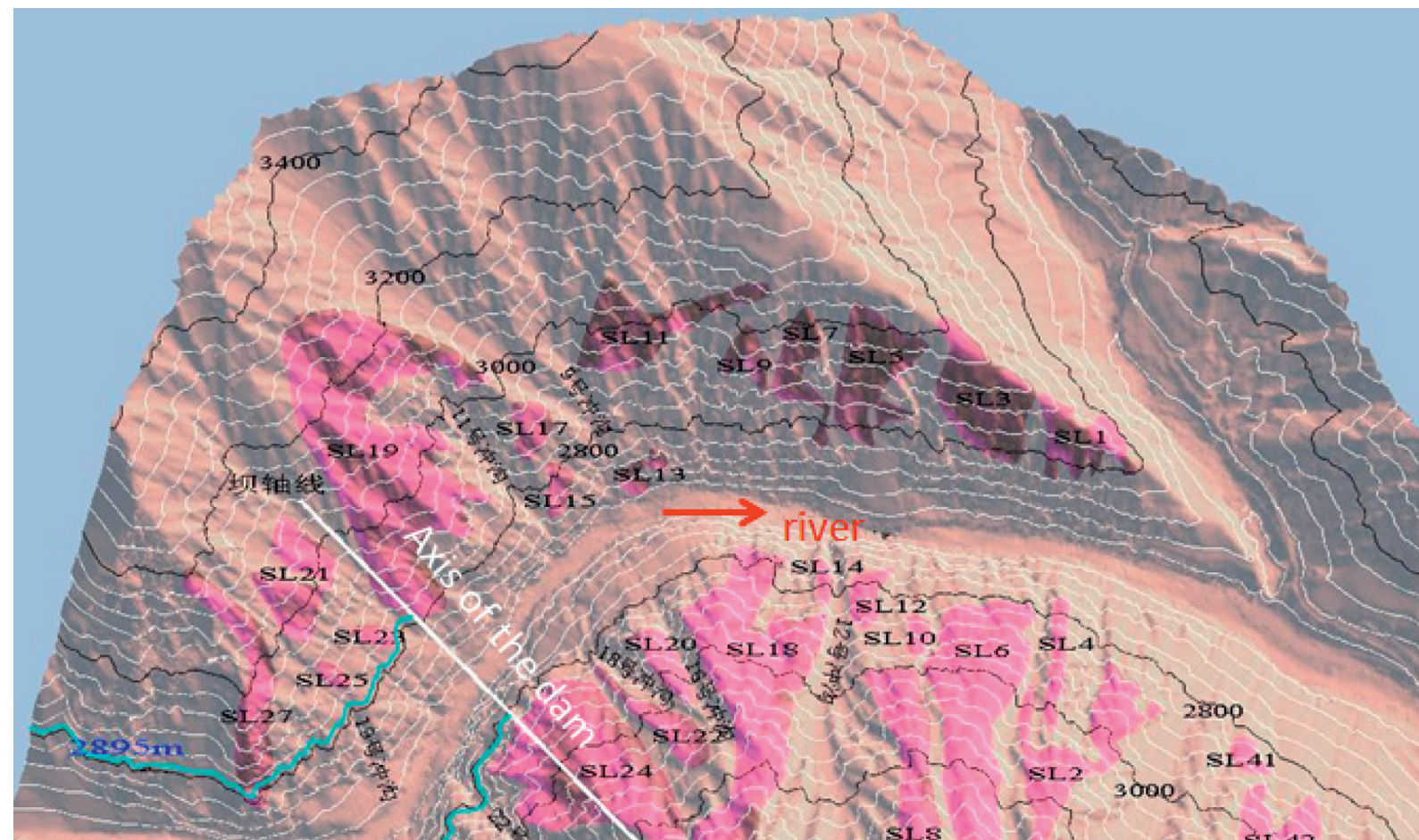

FIGURE 4: Schematic diagram of the distribution of loose rock masses on the slope (the result of 3D laser scanner interpretation, modified after [16]).
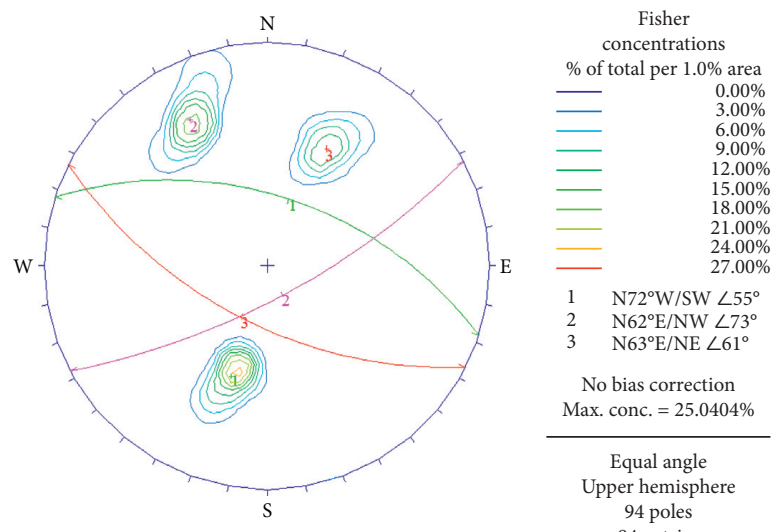

Figure 5: Joint distribution statistics.

expert experience. In hydropower projects, with reference to the relevant specifications, the value is generally based on field tests and the geological conditions of the test site, comprehensively determining the geological recommendations. In the project area, 16 groups of large-scale structural shear tests were carried out, and the test pieces were all $2500 \mathrm{~cm}^{2}$. Following literature [16], the test pieces included 7 groups of hard joints, 2 groups of rock fragments, and 7 sets of cuttings. According to the statistical analysis, the peak shear strengths of joints with hard cementation are $f=0.64-0.85$ and $c=0.21-0.31 \mathrm{MPa}$, and the peak shear strengths of the rock block type weak joints are $f=0.61-0.71$ and $c=0.16-0.25 \mathrm{MPa}$. The shear strength peak strengths of the mud-type weak joints are $f=0.43-0.58$ and $c=0.08-0.18$.

Due to the lack of extensive experimentation, refer to the relevant provisions of Appendix D of the Hydroelectric Power Engineering Geological Survey Specification (GB50287-2016) for the shear strength of joints. The hard joint is based on the average of the small peak intensity values. The weak joint is taken as the small average value of the yield strength, and the standard value of the shear strength of the joints and the probability distribution 


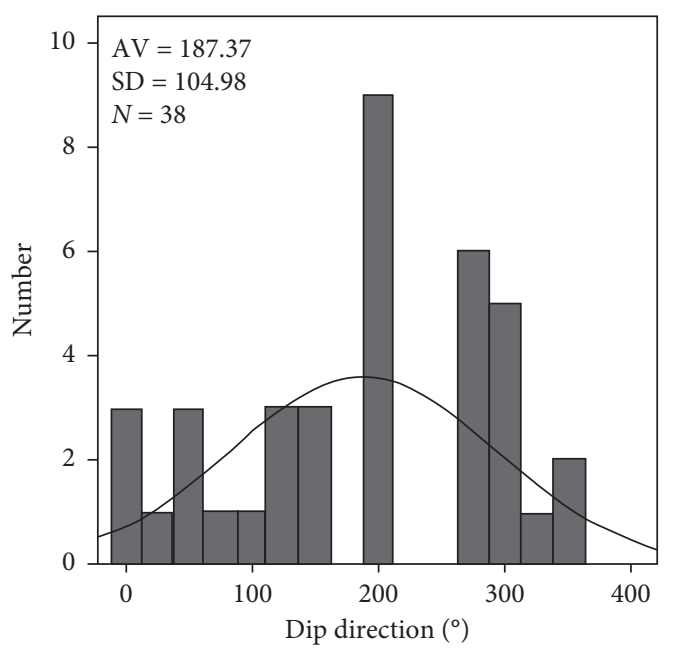

(a)

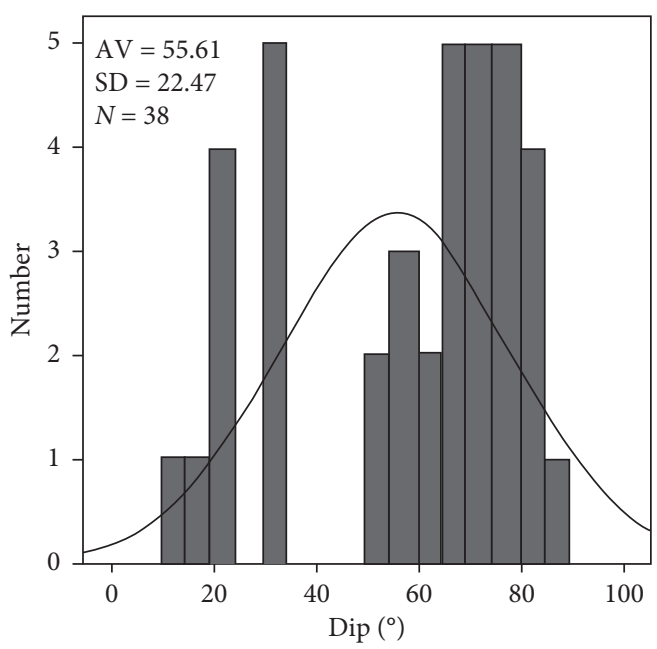

(b)

FIgURE 6: Statistical histogram of the dip direction/dip distribution of joints with grade III.

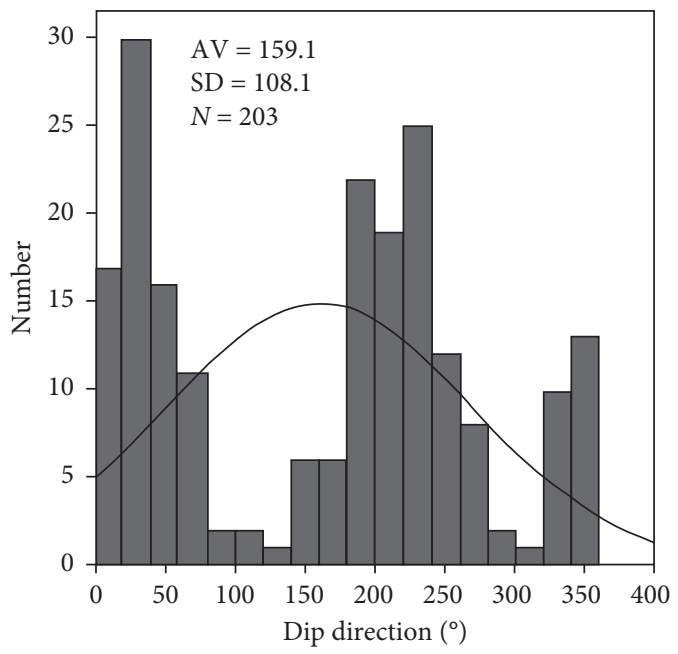

(a)

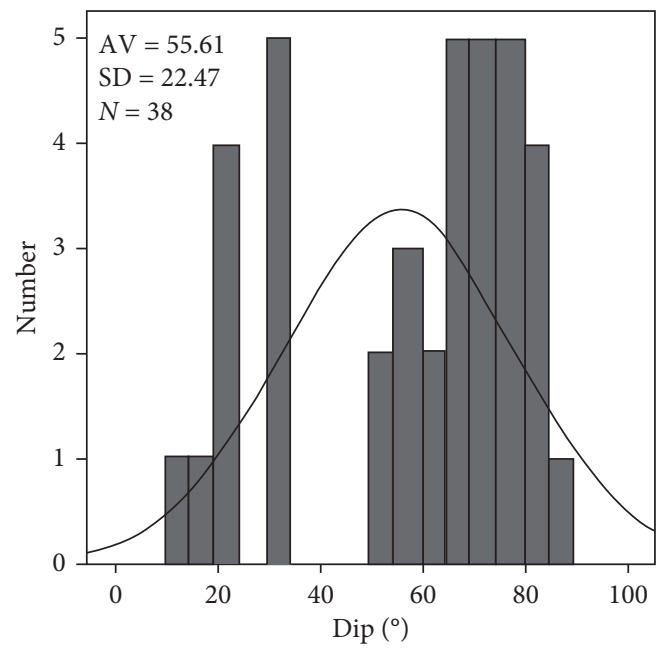

(b)

Figure 7: Statistical histogram of the dip direction/dip distribution of joints with grade IV.

TABLE 1: Distribution characteristics of joints in the study area (SL24).

\begin{tabular}{|c|c|c|c|c|c|c|c|c|c|c|c|}
\hline \multirow[b]{2}{*}{ Set } & \multicolumn{2}{|c|}{ Dip direction $\left({ }^{\circ}\right)$} & \multicolumn{3}{|c|}{$\operatorname{Dip}\left({ }^{\circ}\right)$} & \multicolumn{3}{|c|}{ Trace length (m) } & \multicolumn{3}{|c|}{ Spacing $(\mathrm{m})$} \\
\hline & Form & $\begin{array}{c}\text { Average } \\
\text { value }\end{array}$ & $\begin{array}{l}\text { Standard } \\
\text { error }\end{array}$ & Form & $\begin{array}{l}\text { Average } \\
\text { value }\end{array}$ & $\begin{array}{l}\text { Standard } \\
\text { error }\end{array}$ & Form & $\begin{array}{l}\text { Average } \\
\text { value }\end{array}$ & $\begin{array}{l}\text { Standard } \\
\text { error }\end{array}$ & $\begin{array}{l}\text { Average } \\
\text { value }\end{array}$ & $\begin{array}{c}\text { Standard } \\
\text { error }\end{array}$ \\
\hline 1 & Normal & 205.11 & 5.40 & Normal & 68.96 & 0.85 & Exponential & 4.80 & 0.21 & 0.55 & 0.08 \\
\hline 2 & Normal & 327.56 & 3.34 & Normal & 64.22 & 5.12 & Exponential & 3.02 & 0.14 & 0.43 & 0.06 \\
\hline 3 & Normal & 78.22 & 8.06 & Normal & 38.76 & 5.20 & Exponential & 6.41 & 0.29 & 0.43 & 0.05 \\
\hline
\end{tabular}

characteristics are shown in Table 2. The mechanical parameters of the joints conform to a normal distribution.

4.4. Analysis of Key Block and System Reliability. The key block analysis used in this paper is based on the stereographic projection of vector theory and uses the block theory analysis software BATE 2.0 compiled by Zhang [19]. The joint distribution and mechanical parameter data are shown in Sections 4.2 and 4.3. In addition, the average gravity of the rock mass is $26.30 \mathrm{kN} / \mathrm{m}^{3}$. BATE 2.0 includes a stereographic projection of the vector module. Actually, the joint input in the software and the stereographic projection of the vector shown in Figure 9 can be obtained. In the figure, according to the definition, " 0 " represents the upper surface of the joints participating in the combination to form the rock 


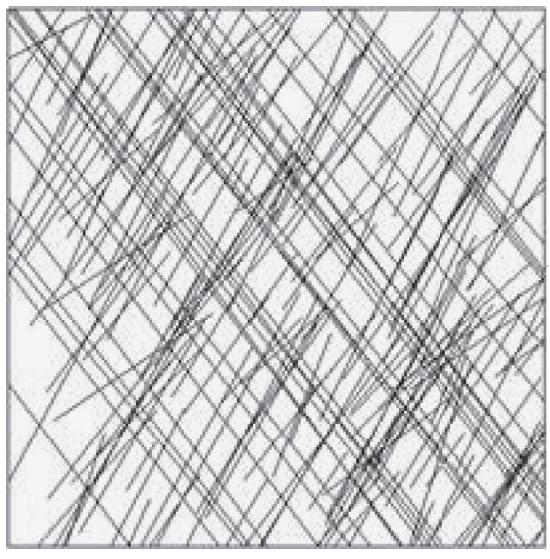

(a)

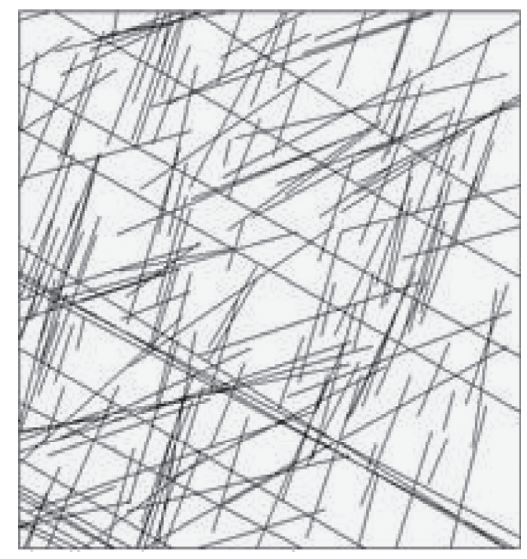

(b)

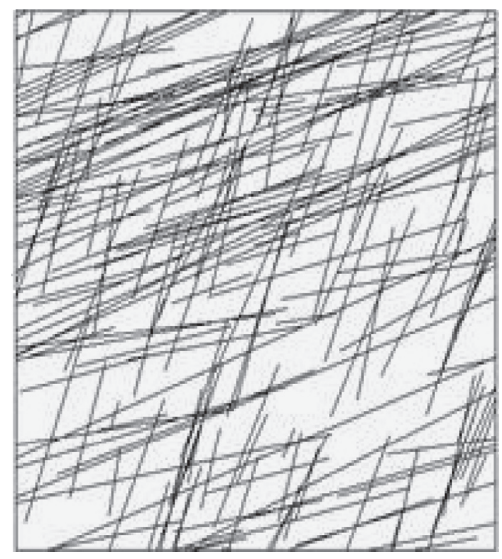

(c)

Figure 8: 3D joint network simulation results. (a) Longitudinal sectional view. (b) Cross-sectional view. (c) Horizon-slice view.

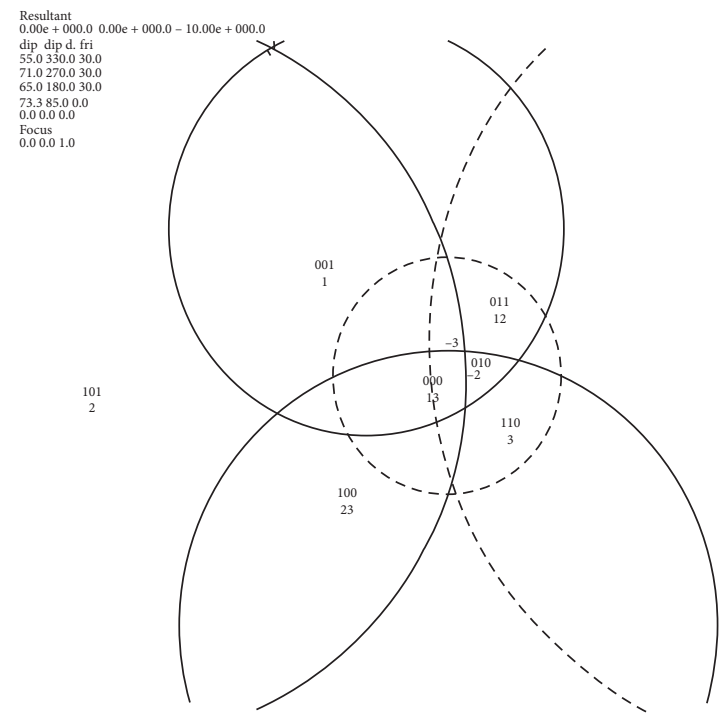

Figure 9: Analysis of the full-space projection of the joints in the study area.

TABLE 2: Characteristics of the shear strength and probability distribution of joints.

\begin{tabular}{lcccccc}
\hline \multirow{2}{*}{$\begin{array}{l}\text { Structural type } \\
\end{array}$} & \multicolumn{2}{c}{$f$} & \multicolumn{2}{c}{ Joints shear strength } & & \multicolumn{2}{c}{$c^{\prime}(\mathrm{MPa})$} \\
& Range & Average value & Standard deviation & Range value & Average value & Standard deviation \\
\hline Cemented & $0.80-0.60$ & 0.68 & 0.008 & $0.250-0.100$ & 0.17 & 0.012 \\
Non-filled & $0.70-0.45$ & 0.59 & 0.012 & $0.150-0.050$ & 0.12 & 0.009 \\
Filled with rock and debris & $0.55-0.45$ & 0.50 & 0.010 & $0.200-0.100$ & 0.16 & 0.009 \\
Filled with debris and mud & $0.45-0.35$ & 0.41 & 0.008 & $0.100-0.050$ & 0.09 & 0.006 \\
Filled with mud and debris & $0.35-0.25$ & 0.33 & 0.008 & $0.050-0.010$ & 0.035 & 0.004 \\
Filled with mud & $0.25-0.18$ & 0.21 & 0.009 & $0.010-0.002$ & 0.009 & 0.002 \\
\hline
\end{tabular}

mass, " 1 " represents the lower surface of the structure participating in the combined formation of the rock mass, and the numerical representation is below the block number. The block slides along the corresponding joints, including single-sided slip and wedge-shaped damage.

Further analysis of these blocks using BATE 2.0 (Table 3) shows that three blocks numbered 100, 011, and 110 are key blocks, and other blocks are movable blocks or infinite blocks. The slope failure mode mainly slides on both sides, that is, the wedge body mainly slides, and the part is singlesided sliding; the support force is not analyzed here. The key block reliability evaluation method discussed in Section 3 should first determine the instability mode of the key block. This judgment is simple when the specific position and the surrounding structure face are known to be cut. Entering respective limit state equations, and then the corresponding 
TABLE 3: Calculation results of key block reliability indicators.

\begin{tabular}{lcccc}
\hline Block & Instability mode & Volume $\left(\mathrm{m}^{3}\right)$ & Instability probability (\%) & Reliability index \\
\hline 100 & Wedge & 8.25 & 2.45 & 1.86 \\
011 & Wedge & 5.42 & 3.35 & 1.77 \\
110 & Single sliding & 6.06 & 0.479 & 4.64 \\
\hline
\end{tabular}

TABLE 4: System reliability index calculation results.

\begin{tabular}{|c|c|c|c|c|c|c|}
\hline \multirow{2}{*}{ Block } & \multicolumn{3}{|c|}{ Instability probability (\%) } & \multicolumn{3}{|c|}{ Reliability index } \\
\hline & Key block & Secondary key block & System block & Key block & Secondary & System block \\
\hline 100 & 2.45 & 0.0083 & 2.54 & 1.86 & 3.71 & 1.74 \\
\hline 011 & 3.35 & 0.0297 & 3.48 & 1.77 & 3.42 & 1.69 \\
\hline 110 & 0.479 & 0.0098 & 0.498 & 2.64 & 4.35 & 2.35 \\
\hline
\end{tabular}

reliability calculation method can be used to evaluate their reliability, and results are shown in Table 3.

Using the reliability relationship between the key block and the secondary key block, the reliability value of the secondary key block and the corresponding step-by-step recursion can be easily calculated. When the calculated block instability probability is less than $0.0005 \%$, the calculation is stopped, and the calculation result is shown in Table 4.

\section{Conclusions}

Cataclastic rock mass stability problem is one of the main engineering geological problems faced by high-slope construction in alpine areas. The unique geological structure of these areas determines the discontinuous characteristics, and stability analysis of such an area needs to systematically consider the rock mass structure. Main conclusions are shown as follows:

(1) Based on the key block theory, the potential unstable block of the slope is divided into key blocks and secondary key blocks, and the system reliability evaluation method is introduced into the evaluation of cataclastic rock mass stability. The method provides an effective and reasonable quantitative evaluation method for the stability analysis of this type of rock slope. A main disadvantage is that the toppling failure mode has not been considered in this method.

(2) With the increase in the probability value of the key block instability, the increase in the instability probability of the system block is obviously larger, which reflects the controlling effect of the key block on the stability of the system block. The calculated system instability probability is slightly larger than the key block instability probability. In the traditional key block theory, only analyzing the key block instability probability is considered to be risk-taking.

(3) A total of 21 cataclastic rock masses are distributed in the study area. The distribution of cataclastic rock masses and joints is mainly carried out by traditional geological surveys and supplemented by $3 \mathrm{D}$ laser scanning. The proposed stability analysis method and analysis results show that the main failure mode in the study area is wedge-shaped damage, and the system reliability is 1.69 .

\section{Data Availability}

The data used to support the findings of this study are included within the article.

\section{Conflicts of Interest}

The authors declare that there are no conflicts of interest regarding the publication of this paper.

\section{Acknowledgments}

This paper was supported by the National Natural Science Foundation of China (51874160) and Discipline Innovation Team of Liaoning Technical University (LNTU20TD-01). This study was also sponsored by Talent Development Program of Kunming University of Science and Technology (no. KKSY201504022).

\section{References}

[1] F.-Q. Wu, "Engineering geology assessment procedure for deformation and stability of high steep rock slopes," Journal of Engineering Geology, vol. 12, no. s1, pp. 199-211, 2004.

[2] A. Canal and M. Akin, "Assessment of rock slope stability by probabilistic-based slope stability probability classification method along highway cut slopes in Adilcevaz-Bitlis (Turkey)," Journal of Mountain Science, vol. 13, no. 11, p. 1893, 2016.

[3] W. Wu, H. Liu, X. Yang et al., "New method to calculate apparent phase velocity of open-ended pipe pile," Canadian Geotechnical Journal, vol. 57, no. 1, pp. 127-138, 2020.

[4] Y. Zhang, X. Yang, W. Wu, M. H. El Naggar, G. Jiang, and R. Liang, "Torsional complex impedance of pipe pile considering pile installation and soil plug effect," Soil Dynamics and Earthquake Engineering, vol. 131, Article ID 106010, 2020.

[5] W. Wu, M. H. El Naggar, M. Abdlrahem, G. Mei, and K. Wang, "New interaction model for vertical dynamic response of pipe piles considering soil plug effect," Canadian Geotechnical Journal, vol. 54, no. 7, pp. 987-1001, 2017. 
[6] K. Wang, W. Wu, Z. Zhang, and C. J. Leo, "Vertical dynamic response of an inhomogeneous viscoelastic pile," Computers and Geotechnics, vol. 37, no. 4, pp. 536-544, 2010.

[7] Z. T. Bieniawski, "Engineering classification of jointed rock masses," The Civil Engineer in South Africa, vol. 15, no. 12, pp. 343-353, 1973.

[8] A. Singh, "FRHI-a system to evaluate and mitigate rockfall hazard in stable rock excavations," Journal of the Institution of Engineers. India. Civil Engineering Division, vol. 85, pp. 62-75, 2004.

[9] R. Hack, D. Price, and N. Rengers, "A new approach to rock slope stability-a probability classification (SSPC)," Bulletin of Engineering Geology and the Environment, vol. 62, no. 2, pp. 167-184, 2003.

[10] G.-H. Shi and R. E. Goodman, "Serigraphic method of stability analysis of rock mass," Science in China, vol. 20, no. 3, pp. 260-271, 1977.

[11] X. Fu, Q. Sheng, H. Tang et al., "Seismic stability analysis of a rock block using the block theory and Newmark method," International Journal for Numerical and Analytical Methods in Geomechanics, vol. 43, no. 7, pp. 1392-1409, 2019.

[12] M. Azarafza, H. Akgün, A. Ghazifard, and E. Asghari-Kaljahi, "Key-block based analytical stability method for discontinuous rock slope subjected to toppling failure," Computers and Geotechnics, vol. 19, pp. 1216-1224, 2019.

[13] J.-C. Cai, N.-P. Ju, R.-Q. Huang et al., "Mechanism of toppling and deformation in hard rock slope: a case of bank slope of hydropower station, Qinghai Province, China," Journal of Mountain Science, vol. 16, no. 4, pp. 924-934, 2019.

[14] R.-X. Zhang, Z.-Q. Li, H.-Z. Zhao et al., "A probabilistic analysis of key block stability in jointed rock masses," Rock and Soil Mechanics, vol. 35, no. 5, pp. 1399-1405, 2014.

[15] S.-Y. Wu, P.-F. Li, and Z.-H. Chen, "Study on the engineering characteristics of cataclastic relaxed rock mass in high-cold canyon," Chinese Journal of Underground Space and Engineering, vol. 14, no. 5, pp. 1250-1257, 2018.

[16] F.-H Gu, "Study on Stability of the Right Bank Slope of Rumei Hydropower Project Based on Rock Discontinuity Property," China University of Geosciences, Wuhan, China, 2018.

[17] Y.-J. Shen, G.-L. Xu, and K.-J. Zhu, "Analysis and application of reliability of blocks based on systematic quantitative methodology," Rock and Soil Mechanics, vol. 32, no. 1, pp. 224-229, 2011.

[18] R.-Q. Huang, F. Lin, D.-J. Chen et al., "Formation mechanism of unloading fracture zone of high slopes and its engineering behaviors," Journal of Engineering Geology, vol. 9, no. 3, pp. 227-232, 2001.

[19] Q.-H. Zhang, Basic Study on Application of Block Theory and Development of Analytical Software, Wuhan University, Wuhan, China, 2004.

[20] J. Zheng, P. H. S. W. Kulatilake, and J. Deng, "Development of a probabilistic block theory analysis procedure and its application to a rock slope at a hydropower station in China," Engineering Geology, vol. 188, pp. 110-125, 2015.

[21] S.-J Qu, "Study on Rock Mass Quality and Deformation Failure Mode of Right Abutment Slope of Rumei Hydropower Station in Tibet," Chengdu University of Technology, Chengdu, China, 2017. 